\title{
Seismic heating signatures in the Japan Trench subduction plate-boundary fault zone: evidence from a preliminary rock magnetic 'geothermometer'
}

\author{
Tao Yang, ${ }^{1,2}$ Mark J. Dekkers ${ }^{2}$ and Bo Zhang ${ }^{1}$ \\ ${ }^{1}$ Key Laboratory of Seismic Observation and Geophysical Imaging, Institute of Geophysics, China Earthquake Administration, No. 5 Minzu Daxue Nanlu, \\ Haidian District, Beijing 100081, China.E-mail: yangtao@cea-igp.ac.cn \\ ${ }^{2}$ Paleomagnetic Laboratory Fort Hoofddijk, Department of Earth Sciences, Utrecht University, Budapestlaan 17, NL-3584 CD, Utrecht, The Netherlands
}

Accepted 2016 January 11. Received 2015 December 2; in original form 2015 July 20

\begin{abstract}
SUMMAR Y
Frictional heating during earthquake rupture reveals important information on earthquake mechanisms and energy dissipation. The amount of annealing varies widely and is, as yet, poorly constrained. Here we use magnetic susceptibility versus temperature measurements during cycling to increasingly elevated temperatures to constrain the maximum temperature a slip zone has experienced. The case study comprises sheared clay cored from the Japan Trench subduction plate-boundary fault zone (décollement), which accommodated the large slip of the $2011 M_{\mathrm{w}} 9.0$ Tohoku-oki earthquake. The décollement was cored during the Integrated Ocean Drilling Program (IODP) Expedition 343, the Japan Trench Fast Drilling Project (JFAST). Heating signatures with estimated maximum temperatures ranging from $\sim 300$ to over $500^{\circ} \mathrm{C}$ are determined close to the multiple slip surfaces within the décollement. Since it is impossible to tie a specific slip surface to a certain earthquake, thermal evidence for the cumulative effect of several earthquakes is unveiled. This as yet preliminary rock magnetic 'geothermometer' would be a useful tool to detect seismic heating along faults that experienced medium temperature rise, a range which is difficult to assess with other approaches.
\end{abstract}

Key words: Rock and mineral magnetism; Ocean drilling; Friction; Rheology and friction of fault zones; Heat generation and transport; Fractures and faults.

\section{INTRODUCTION}

The Japan Trench, where the Pacific Plate subducts beneath the North American Plate at a convergence rate of $85 \mathrm{~mm} \mathrm{yr}^{-1}$ (Argus et al. 2011; Fig. 1a), is one of the seismically most active regions around Japan (e.g. Hashimoto et al. 2009; Simons et al. 2011). The $2011 M_{\mathrm{w}} 9.0$ Tohoku-oki earthquake off the northeast coast of Honshu island (Japan, Fig. 1a) induced huge coseismic slip $(\sim 50 \mathrm{~m})$ on the shallow portion of the megathrust in the Japan Trench subduction zone (e.g. Fujiwara et al. 2011; Yue \& Lay 2011), which caused an unprecedentedly devastating tsunami in Japan (e.g. Simons et al. 2011). To understand the earthquake's physical mechanisms and dynamics, the Integrated Ocean Drilling Program (IODP) Expedition 343, the Japan Trench Fast Drilling Project (JFAST), was undertaken within 13 months after rupture of the earthquake (Chester et al. 2013a). During this expedition, the plate-boundary fault zone (décollement) which accommodated the large slip of the Tohoku-oki earthquake, was penetrated and partly cored at Site C0019 (Fig. 1a). The site is located approximately $93 \mathrm{~km}$ seaward of the main shock epicentre, and approximately $6 \mathrm{~km}$ landward of the trench axis.
Knowing how much temperature rise is induced by frictional heating during fault slip is important for our understanding of faulting mechanisms and to constrain earthquake energy budgets (Mair et al. 2006). Other than direct borehole temperature measurements across a fault zone (e.g. Kano et al. 2006; Fulton et al. 2013), recently developed alternative approaches to detect fault heating include fission track signatures (e.g. d'Alessio et al. 2003), trace element partitioning (e.g. Ishikawa et al. 2008), thermal decarbonation (e.g. Han et al. 2007), clay mineral reactions (e.g. Kuo et al. 2011), vitrinite reflectance (e.g. Sakaguchi et al. 2011), and biomarker thermal maturity (e.g. Savage et al. 2014). The applicability of each of these methods is dependent on the lithology of the fault zone, and temperatures that are identifiable with most of these techniques are rather low, that is $<250-300^{\circ} \mathrm{C}$ (see also Section 5.3).

This leaves the temperature range between frictional melting (generally $>1000^{\circ} \mathrm{C}$ ) and $300^{\circ} \mathrm{C}$ essentially unchartered. Here, magnetic mineralogy may be utilized advantageously. Magnetic minerals - more strictly ferrimagnetic minerals - magnetite $\left(\mathrm{Fe}_{3} \mathrm{O}_{4}\right)$, maghemite $\left(\gamma-\mathrm{Fe}_{2} \mathrm{O}_{3}\right)$, pyrrhotite $\left(\mathrm{Fe}_{7} \mathrm{~S}_{8}\right)$ or greigite $\left(\mathrm{Fe}_{3} \mathrm{~S}_{4}\right)$, occur in trace amounts in any rock. Importantly, they can be measured down to very low concentrations, in the ppm-range, 


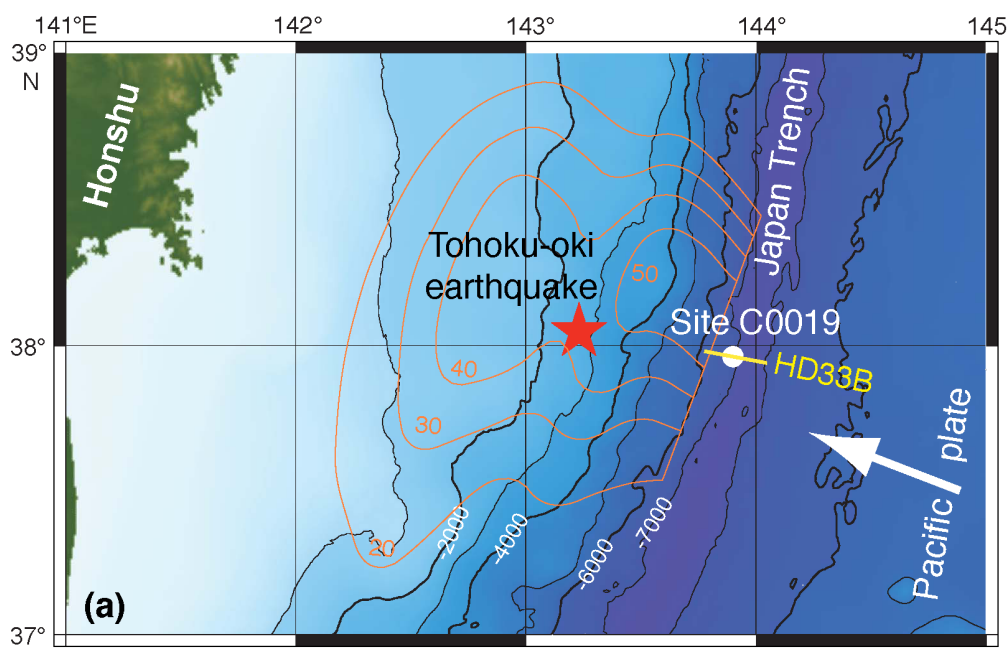

\section{(c) Unit 4 (core 17R)}
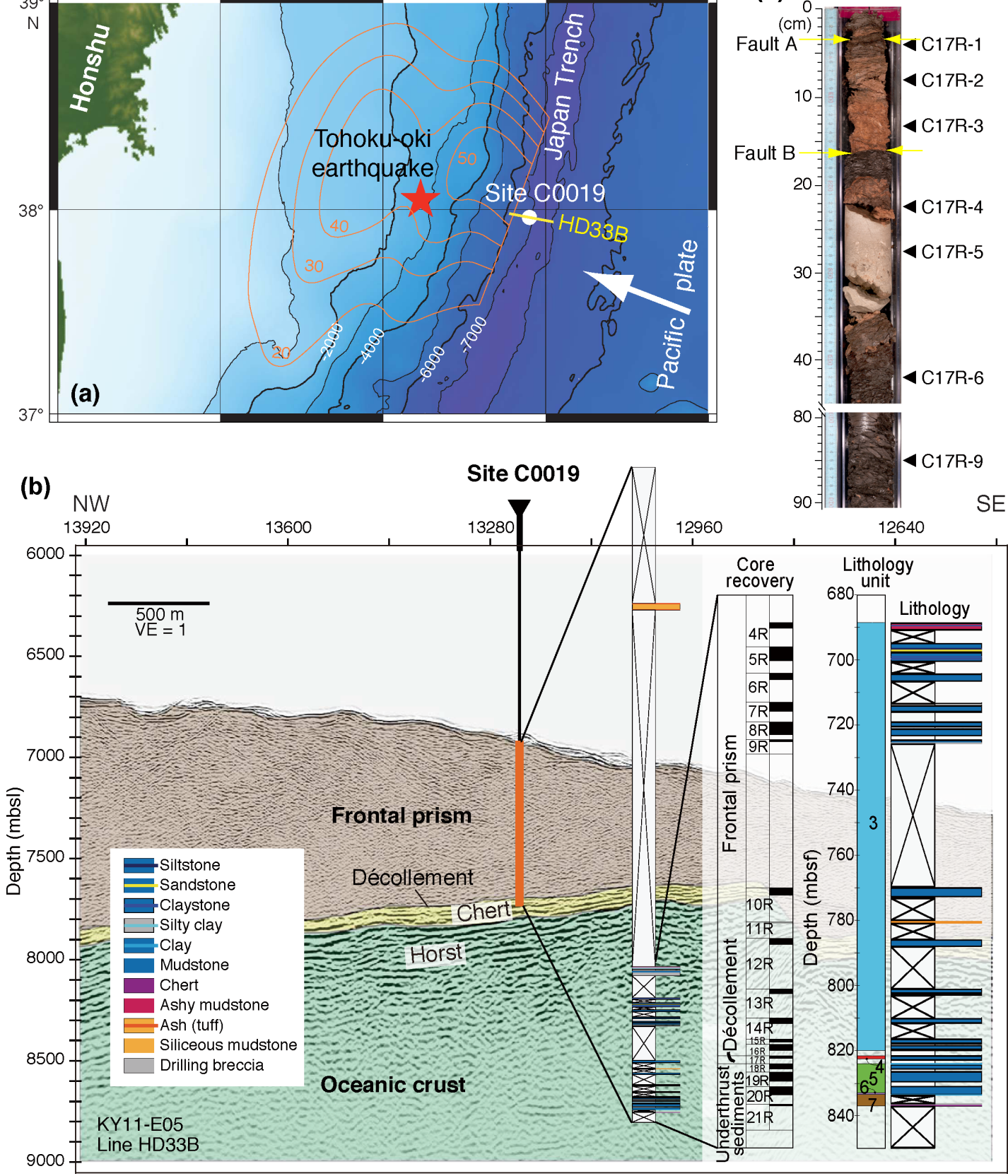

Figure 1. (a) Map of Japan Trench, showing location of Site C0019 with white filled circle. The red star indicates the epicentre of the $2011 M_{\mathrm{w}} 9.0$ Tohoku-Oki earthquake. Contours of slip during the earthquake rupture are taken from Yue \& Lay (2011). White arrow indicates the plate convergence vector (Argus et al. 2011). (b) Seismic profile and overlain interpretation along Line HD33B [indicated in Fig. 1(a)], showing location of site cored during IODP Expedition 343. Inset shows the lithology and recovery at cored interval of Hole C0019E (688.50-836.81 mbsf). The dark parts indicate core recovered, with adjacent numbers indicating core numbers [R indicates the core type (bit type), here rotary core barrel]. VE: vertical exaggeration, mbsl: meters below sea level (compiled from Lin et al. 2014). (c) Core photos show sheared clay in plate-boundary décollement (Unit 4, core 17R) with sampling points marked by triangles. Yellow arrows indicate the locations of two faults identified by Kirkpatrick et al. (2015).

with today's sensitive magnetometers. Further, certain magnetic parameters are a function of grain size, so that grain-size dependent information can be retrieved from bulk samples, impossible with most other techniques (e.g. Dunlop \& Özdemir 1997; Tauxe 2010). For instance, grinding of a rock under the action of rupturing which would lead to fining of grain sizes is detectable in a bulk sample with mineral-magnetic means. The formation of these magnetic minerals is strongly temperature-dependent as well (Hirt et al. 1993; Hrouda et al. 2003; Spassov \& Hus 2006). So, small changes in the magnetic mineral content of a rock may be related to the peak temperature that rock has experienced. Under the conditions of interest here, magnetite is expected to be most important. For example, if a clay mineral (partially) reacts due to changes in temperature, the trace amounts of magnetite that are formed as a consequence can be measured. If a rock once has been heated to a certain temperature in nature, reheating to a lower temperature will not induce further change, actually the underlying rationale of all geothermometers. The minerals with higher decomposition/conversion temperatures 
would remain thermally stable. In general, the thermochemical expression of magnetic phases in a rock is reflected directly in temperature-dependent variations in mineral magnetic parameters, for example, the magnetic susceptibility $(\chi)$ and so-called hysteresis loops. Hysteresis loops trace the magnetic response of a sample to an applied magnetic field gradually changing from say +1 Tesla to -1 Tesla (the same field strength in opposite direction) and back to +1 Tesla. For reference the strength of the Earth's magnetic field is $\sim 50 \mu \mathrm{T}$. Hysteresis loops contain information on the amount of the magnetite as well as on its grain size [for further explanation (and also of other principles and terminology) see the Appendix]. When a rock is heated again in laboratory, its magnetic mineralogy should not change unless it is heated over the maximum temperature it underwent in nature (Hrouda et al. 2003; Spassov \& Hus 2006).

Relying on the aforementioned notions, here we present a method that exploits the temperature dependence of magnetic susceptibility $(\chi-T)$ during temperature cycles to increasingly elevated maximum temperatures to estimate the maximum temperature experienced by a fault. Low temperatures should result in reversible heating and cooling segments of $\chi-T$ runs. If the maximum temperature in the laboratory surpassed the natural heating experienced by a rock, the magnetic phases will be altered, that is either (partially) destroyed or, on the contrary, some neoformation of magnetic phases may occur. Both scenarios are leading to irreversible heating and cooling segments in $\chi-T$ runs. The amount of irreversibility can be substantial. It should be realized that cumulative temperature-time effects as a consequence of repeated rupture along a certain slip zone are very difficult to track by a laboratory-derived parameter. Therefore temperatures should be considered as an upper bound of the 'natural' temperature. Since the rupture duration is of the same order of magnitude as the time spent at the maximum temperature (minutes) during the stepwise $\chi-T$ runs, the temperatures determined are plausible. As a rock magnetic 'geothermometer', stepwise $\chi-T$ runs open up a new tool for detection of seismic frictional heating, predominantly in a temperature range that is not covered by other methods, and in lithologies where other methods might not be applicable.

A temperature anomaly (of $\sim 0.31^{\circ} \mathrm{C}$ ) attributed to frictional heating by the 2011 Tohoku-oki earthquake has been measured at the depth interval of $812-820 \mathrm{~m}$ below sea floor (mbsf) in Hole C0019D drilled in the Japan Trench plate-boundary fault zone during IODP Expedition 343, 16 months after the earthquake (Fulton et al. 2013). Multiple localized slip surfaces have been identified in cored sediments (Kirkpatrick et al. 2015; Rabinowitz et al. 2015). Through access to the cored material, here we demonstrate the efficacy of the $\chi-T$ 'geothermometer' for detecting frictional heating signatures of several earthquakes that have occurred along the plateboundary fault zone, which furthers our understanding of the energy dissipation by these earthquakes.

\section{GEOLOGICAL BACKGROUND AND SA M P L ES}

Site C0019 is located at the toe of the frontal prism in the area of large shallow slip during the Tohoku-oki earthquake (Figs 1a and b). Five holes were drilled; among them, Hole C0019B served for logging and measurement while drilling, while in Hole C0019D a miniature temperature logger observatory was deployed. Actual core segments were retrieved from Hole C0019E that is $\sim 30 \mathrm{~m}$ away from Hole C0019D along the trench strike. JFAST successfully drilled and collected approximately $55 \mathrm{~m}$ of discontinuous core at the interval of $175 \sim 835 \mathrm{mbsf}$ that spans the frontal prism, décollement and underthrust sediments (Chester et al. 2013a). The sediments have been grouped into seven lithologic units (Fig. 1b). Units $1-3$ are prism sediments and comprise mainly mudstone and siliceous mudstone. Unit 4 mostly consists of strongly sheared clays. Units 5-7 are underthrust sediments; Unit 5 is brown mudstone; Unit 6 is pelagic clay; Unit 7 consists of laminar chert of yellowbrown and chocolate-brown colour. Chester et al. (2013a) provided detailed descriptions of each unit.

Among these units, Unit 4 (core 17R, depth interval: 821.5$822.5 \mathrm{mbsf}$ ) is comprised predominantly of sheared clay with a unique scaly fabric. One short interval of more competent mudstone occurs (Fig. 1c), which is composed of $\sim 40$ per cent silt and $\sim 60$ per cent clay (Kirkpatrick et al. 2015). Unit 4 separates the deformed sediments of the frontal prism above and the relatively undisturbed pelagic strata of the subducting Pacific Plate below, as demonstrated by structural and sedimentological observations (Chester et al. 2013a,b; Kirkpatrick et al. 2015) and anisotropy of magnetic susceptibility analysis (Yang et al. 2013). It is interpreted as the plate-boundary fault zone with an estimated thickness of $4.86 \mathrm{~m}$ deduced from the distance the drill bit advanced (Chester et al. 2013a). Core recovery of this zone was unfortunately only partial. Therefore, the recovered sediments do not necessarily contain the principal slip zone of the Tohoku-oki earthquake (Chester et al. 2013b; Kirkpatrick et al. 2015). The scaly clay displays two distinct colours: bright reddish orange-brown and dark chestnut brown to almost black. Both coloured zones are dominated by smectite ( $>70$ per cent) (Kameda et al. 2015); compositional differences are likely due to higher contents of $\mathrm{Fe}$ or Mn oxides in the dark brown clay (Kirkpatrick et al. 2015).

At least four discrete slip surfaces have been identified or inferred within the upper part of the core 17R by Kirkpatrick et al. (2015; Fig. 1c): Fault A is defined as a $\sim 1$-cm-thick zone located $\sim 3-$ $4 \mathrm{~cm}$ from the top of core, where the spaced cleavage is obliterated, and the clay is composed of equant, $\leq 1 \mathrm{~mm}$ long, angular blocks with no preferred orientation. Fault B is defined by a sharp contact between the orange-brown and dark brown clays $\sim 16 \mathrm{~cm}$ below the top of core. In addition, two tectonic contacts at the upper and lower boundaries of the mudstone interval are also inferred to be faults, which are obscured by drilling disturbance (Kirkpatrick et al. 2015).

In this study, 29 samples were collected from Units 3, 4 and 5, including ten samples from the interval of $810.15-819.51 \mathrm{mbsf}$ in the frontal prism sediments of Unit 3, ten samples from Unit 4, and nine samples from Unit 5 underthrust sediments in the interval of 824.37-832.83 mbsf. Within Unit 4, the plate-boundary fault zone, four samples were collected from different distances to Faults $\mathrm{A}$ and B (Fig. 1c): C17R-1 (0.5 cm above Fault A), C17R-2 (7.5 cm above Fault B), C17R-3 (2.5 cm above Fault B) and C17R-4 (6.5 cm below Fault B). The six other samples include C17R-5 from the central part of the mudstone interval, while C17R-6 through C17R-10 are collected from the lower part of core $17 \mathrm{R}$.

\section{METHODS}

All samples' low $(976 \mathrm{~Hz})$ and high $(15616 \mathrm{~Hz})$ frequency magnetic susceptibilities ( $\chi_{\text {If }}$ and $\chi_{\mathrm{hf}}$, respectively, expressed on a massspecific basis) were measured with an MFK1-FA Multi-Function Kappabridge susceptometer (AGICO, Brno, Czech Republic) with a detection limit of $2 \times 10^{-8} \mathrm{SI}$ and a measurement accuracy of 0.1 per cent, at a field intensity of $200 \mathrm{~A} \mathrm{~m}^{-1}$ (peak-to-peak). Frequency dependence of magnetic susceptibility ( $\chi_{\text {fd }}$ per cent $)$ was calculated as 
$\chi_{\mathrm{fd}}$ per cent $=\left[\left(\chi_{\mathrm{lf}}-\chi_{\mathrm{hf}}\right) / \chi_{\mathrm{lf}}\right] \times 100 . \chi_{\mathrm{lf}}$ is taken as the mass-specific low-field magnetic susceptibility $(\chi)$. Magnetic hysteresis loops and back-field isothermal remanent magnetization curves were measured to determine the hysteresis parameters, coercive force $\left(B_{\mathrm{c}}\right)$, remanence coercive force $\left(B_{\mathrm{cr}}\right)$, saturation remanence $\left(M_{\mathrm{rs}}\right)$ and saturation magnetization $\left(M_{\mathrm{S}}\right)$ using a MicroMag ${ }^{\mathrm{TM}}$ Model 3900 vibrating sample magnetometer (VSM, Princeton Measurements Corp.). The maximum applied field was 1.0 T. First-order reversal curves (FORCs) were measured with the VSM 3900 to evaluate magnetostatic interactions and further assess the magnetic domain state. For each FORC diagram, 120 curves were measured with an averaging time of $0.5-1$ second per data point and a field increment of $4 \mathrm{mT}$. FORC diagrams were processed using the FORCinel package (Harrison \& Feinberg 2008) to identify regions of the FORC distribution.

The $\chi-T$ measurement of 18 representative samples was completed with a MFK1-FA Kappabridge susceptometer operating at a field of $200 \mathrm{~A} \mathrm{~m}^{-1}$ and a frequency of $976 \mathrm{~Hz}$ with a CS-4 hightemperature furnace attached to it. Samples were heated to $700^{\circ} \mathrm{C}$ in argon of standard laboratory quality (the flow rate is about $100 \mathrm{ml}$ $\min ^{-1}$ ) with a heating rate of approximately $11^{\circ} \mathrm{C} \mathrm{min}^{-1}$, and subsequently cooled to room temperature. To determine the temperature at which the magnetic mineralogy is altered during the experiment and to relate that to the temperatures generated by the seismic frictional heating, seven samples from the core $17 \mathrm{R}$ were subjected to partial heating/cooling thermomagnetic cycles to progressively increasing temperatures (subsequently to 200, 300, 400, 500, 600 and finally to $700^{\circ} \mathrm{C}$ ) referred to as 'incremental $\chi-T$ cycles'.

A reversible incremental $\chi-T$ cycle implies that the maximum temperature of that cycle is lower than the temperature the sample experienced in natural conditions. This interpretation is subject to some further constraints. Many 'unheated' sediments will show irreversible $\chi-T$ cycles as well above certain temperatures, for example when organic matter is carbonized $\left(T>400^{\circ} \mathrm{C}\right.$, e.g. Hanesch et al. 2006) or when pyrite alters to pyrrhotite in inert atmosphere ( $T>500{ }^{\circ}$ C, e.g. Tanikawa et al. 2008). As will be shown later (Sections 4.1 and 5.1) fault slip leads to ultrafine magnetic particles with a high $\chi_{\mathrm{fd}}$ per cent and distinct hysteresis properties that are not measured for 'normal' sediment. Therefore the reversibility of $\chi-T$ cycles should be evaluated in conjunction with hysteresis parameters. To evaluate the amount of magnetomineralogical changes due to laboratory heating and calculate the reversibility of the heating and cooling runs for each maximum temperature, two alteration parameters are defined (Hrouda 2003; Spassov \& Hus 2006). The first one is termed $\delta_{\chi}$; it measures the relative change in $\chi$ after a given heating/cooling cycle. It is defined as:

$\delta_{\chi} \%=\frac{\left|\chi_{\mathrm{AH}}-\chi_{0}\right|}{\chi_{0}} \times 100$

where $\chi_{0}$ and $\chi_{\mathrm{AH}}$ are the magnetic susceptibility before heating and after heating, that is the final value of the cooling branch, respectively. The second parameter is termed $\delta_{\text {curve }}$. It evaluates the reversibility of corresponding heating and cooling branches through measuring the area enclosed by the heating and cooling branches:

$\delta_{\text {curve }} \%=\frac{\int_{T_{0}}^{T_{m}}\left|\chi_{c}(T)-\chi_{h}(T)\right| \mathrm{d} T}{\int_{T_{0}}^{T_{m}} \chi_{h}(T) \mathrm{d} T} \times 100$,

where $\chi_{h}(T)$ and $\chi_{c}(T)$ are $\chi$ values at temperature $T$ on the heating and cooling branches, respectively. $T_{0}$ and $T_{m}$ are room temperature and the maximum treatment temperature for each run, respectively. The smaller the $\delta_{\text {curve }}$ value, the more reversible the heating and cooling branches. Fully reversible curves have a $\delta_{\text {curve }}$ value of zero. Here a value of $>10$ per cent in $\delta_{\chi}$ or $\delta_{\text {curve }}$ will be regarded as an indication of significant magnetic mineralogical alteration.

\section{RESULTS}

\subsection{Rock magnetic properties}

Downhole magnetic parameters of sediment samples are shown in Fig. 2. It is evident that sheared clays from the plate-boundary fault zone have $\chi, M_{\mathrm{s}}$ and $M_{\mathrm{rs}}$ values comparable to those from frontal prism and underthrust sediments. Their $\chi_{\mathrm{fd}}$ per cent values are higher, however, and their $B_{\mathrm{c}}$ and $B_{\mathrm{cr}}$ values are markedly lower. Hysteresis loops of sheared clay samples (Figs $3 a-c$ and S1a-c) are much 'thinner' than those from frontal prism (Figs 3d, S2a and b) and underthrust sediments (Figs 3e and S2c), which is in line with their much lower $B_{\mathrm{c}}$ values (Fig. 2). However, all loops are closed and approach magnetic saturation in a field of $\sim 300$ $\mathrm{mT}$, indicating that the magnetic minerals are dominated by lowcoercivity ferrimagnetic mineral.

FORC diagrams of prism sediments (Figs 3i, S2d and e) and underthrust sediments (Figs $3 \mathrm{j}$ and S2f) are characterized by contours that start to diverge away from the origin and show a larger spread along the $B_{\mathrm{u}}$ axis. Some asymmetry is noticeable. This contour pattern is consistent with the behaviour of typical interacting pseudo-single domain (PSD) magnetic particles (Pike et al. 1999; Roberts et al. 2014). FORC diagrams for most sheared clays show similar divergent and asymmetrical contours (Figs 3f, g, S1e and g) but $B_{\mathrm{c}}$ density maxima are shifted to lower values, compatible with finer particles. All sheared clays present a relatively narrow spreading along the $B_{\mathrm{u}}$ axis and a rather confined distribution along the $B_{\mathrm{c}}$ axis. Occasionally a central ridge-like distribution along the $B_{\mathrm{c}}$ axis is observed (Figs $3 \mathrm{~h}$ and S1f). This is consistent with a population consisting predominantly of single-domain (SD) magnetite with little magnetic interaction (Egli et al. 2010; Roberts et al. 2014).

\section{$4.2 \chi-T$ cycles to stepwise increasingly elevated temperatures}

$\chi-T$ cycles from room temperature to $700^{\circ} \mathrm{C}$ of representative samples are shown in Figs $3 \mathrm{k}-\mathrm{O}, \mathrm{S} 1 \mathrm{i}-1$ and $\mathrm{S} 2 \mathrm{~g}-\mathrm{i}$. On the heating branches, $\chi$ gradually increases to up to approximately $450{ }^{\circ} \mathrm{C}$, which might be due to improved crystallinity as a consequence of the removal of lattice vacancies by the heating and/or detachment of adsorbed iron in clay minerals with neoformation of ferrimagnetic minerals, and decreases to nearly zero at about $580^{\circ} \mathrm{C}$, the Curie temperature of magnetite (Dunlop \& Özdemir 1997). So, magnetite is the dominant magnetic carrier. It is also worth noting that $\chi$ is distinctly increasing below $320^{\circ} \mathrm{C}$ on the final cooling branch of sample CR17-6 (Figs S1k and S3d), which is consistent with the Curie temperature of pyrrhotite. In general two $\chi-T$ types are identified: prism sediments, underthrust sediments and most of sheared clay (i.e. C17R-1, C17R-5, C17R-6 and C17R-9) have a much higher susceptibility during the cooling branches than during the corresponding heating branches (Figs 3m-o, S1i, k, 1 and S2g-i). In contrast, samples C17R-2 (Fig. 3k), C17R-4 (Fig. 31) and C17R-3 (Fig. S1j), which are very close to the Faults A and B in the upper part of core 17R (Fig. 1c) show the opposite pattern: their $\chi$ values on the cooling branches are clearly lower than on the heating branches. After heating to $700^{\circ} \mathrm{C}$, a small decrease in 


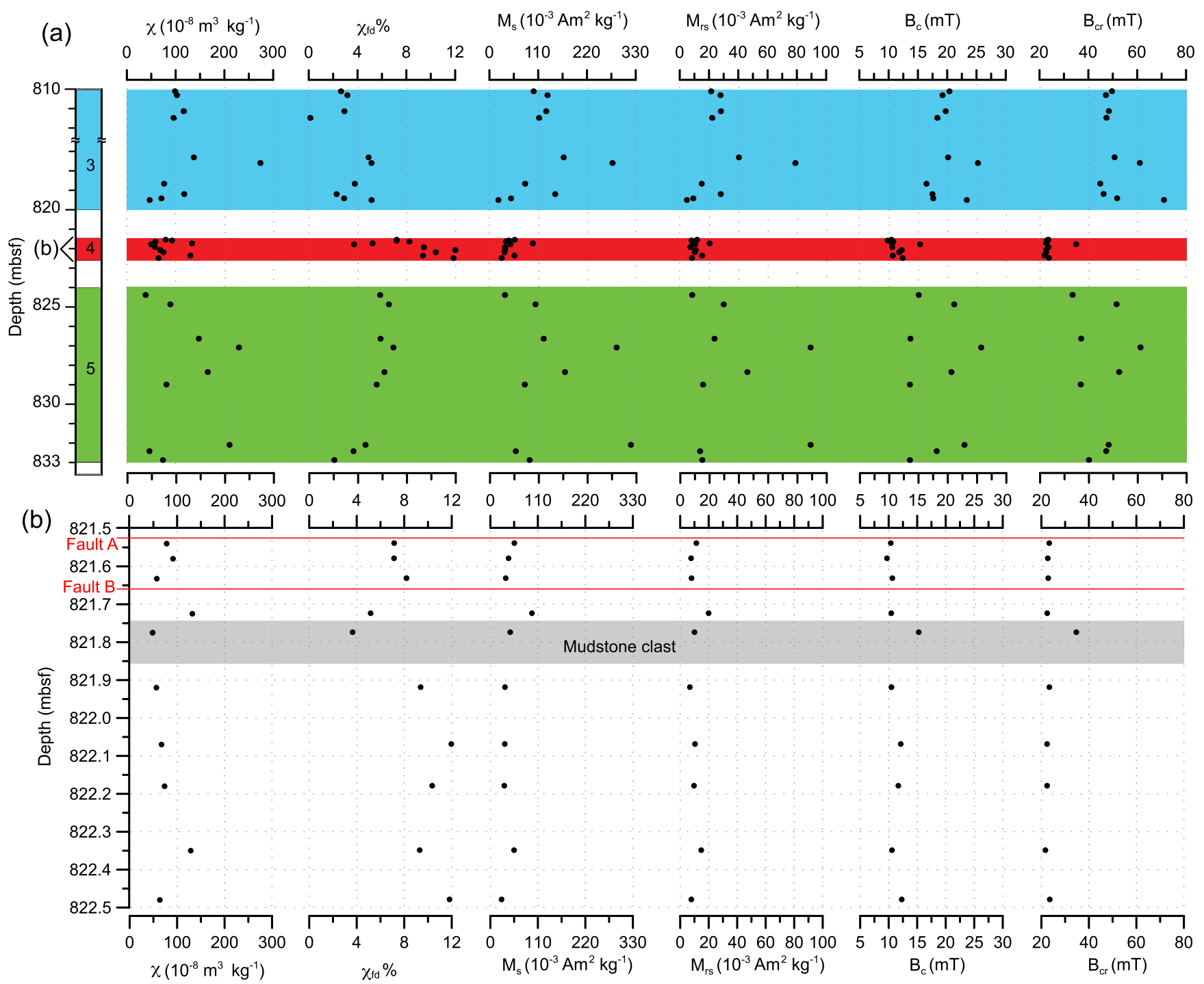

Figure 2. Magnetic properties of units 3-5 (810-833 mbsf) from the JFAST borehole C0019E. (a) (left- to right-hand side) Lithological unit allocation from Chester et al. (2013a), downhole mass-specific low-field magnetic susceptibility $(\chi)$, frequency-dependent magnetic susceptibility $\left(\chi_{\mathrm{fd}}\right.$ per cent), saturation magnetization $\left(M_{\mathrm{s}}\right)$, saturation remanence $\left(M_{\mathrm{rs}}\right)$, coercive force $\left(B_{\mathrm{c}}\right)$ and remanent coercive force $\left(B_{\mathrm{cr}}\right)$. (b) Detailed view of data from (a) within Unit 4. Red lines indicate the locations of two observed faults shown in Fig. 1(c). Note: Frequency-dependent magnetic susceptibilities were measured at two frequencies, 976 (low) and $15616 \mathrm{~Hz}$ (high), with a MFK1-FA Kappabridge susceptometer; thus, here $\chi_{\mathrm{fd}}$ per cent is 1.6 times that obtained with a Bartington MS2B sensor, which operates at $465 \mathrm{~Hz}$ (low frequency) and $4650 \mathrm{~Hz}$ (high frequency).

$\chi$ is measured, which may due to the partial conversion of magnetite to hematite during the heating. It suggests that sediments close to the faults seem to have been heated to higher temperatures than those further out, which will be further discussed in Section 5.4 .

The heating and cooling $\chi-T$ cycles to increasingly higher temperatures of samples C17R-2, C17R-4 and C17R-9 are shown in Fig. 4; the other four samples processed are in Fig. S3. The heating curves of the next run duplicate the cooling curves of the previous run. The thermochemical alteration is evaluated by the afore-defined alteration parameters $\delta_{\chi}$ and $\delta_{\text {curve }}$. In samples C17R-1 $(0.5 \mathrm{~cm}$ above Fault A) and C17R-3 and C17R-4 (2.5 cm above and $6.5 \mathrm{~cm}$ below Fault B, respectively), the heating and cooling curves for each step are virtually identical (Figs $4 \mathrm{~b}, \mathrm{~S} 3 \mathrm{a}$ and b) during cycles up to $500^{\circ} \mathrm{C}$. Both $\delta_{\chi}$ and $\delta_{\text {curve }}$ change by just a few per cent. A distinct increase in these parameters is observed when heated to $600{ }^{\circ} \mathrm{C}$ (Table 1, Figs 4e, S3e and f). This indicates that maximum temperature these samples experienced in nature was between 500 and $600{ }^{\circ} \mathrm{C}$. For sample C17R-2, which is $7.5 \mathrm{~cm}$ above Fault B, minor changes $\left(<10\right.$ per cent) in $\delta_{\chi}$ and $\delta_{\text {curve }}$ are observed until heating up to $400{ }^{\circ} \mathrm{C}$ (Table 1 , Fig. $4 \mathrm{a}$ ). After heating to $500^{\circ} \mathrm{C}$, a significant increase in $\chi$ is observed on the cooling branch close to room temperature: $\delta_{\chi}$ increases to 13 per cent. $\delta_{\text {curve }}$ does not show yet any substantial increase (Table 1, Fig. $4 d$ ). This would point to a maximum temperature in nature between 400 and $500{ }^{\circ} \mathrm{C}$. Samples C17R-9 (Fig. 4c) and C17R-6 (Fig. S3d) show already more than 10 per cent change in $\delta_{\chi}$ when they are heated to $400^{\circ} \mathrm{C}$, although $\delta_{\text {curve }}$ does not show any substantial increase after a cycle to that temperature. Both $\delta_{\chi}$ and $\delta_{\text {curve }}$ are markedly increasing with annealing temperature of $500{ }^{\circ} \mathrm{C}$ and higher (Table 1, Figs $4 \mathrm{f}$ and $\mathrm{S} 3 \mathrm{~h})$. This would imply a lower maximum exposure temperature in nature for C17R-6 and -9 than for C17R-1, C17R-2, C17R-3 and $\mathrm{C} 17 \mathrm{R}-4$. The mudstone clast (C17R-5) has a relatively low starting $\chi$, however, a $\sim 12$ per cent of $\delta_{\chi}$ is observed after it is heated to 

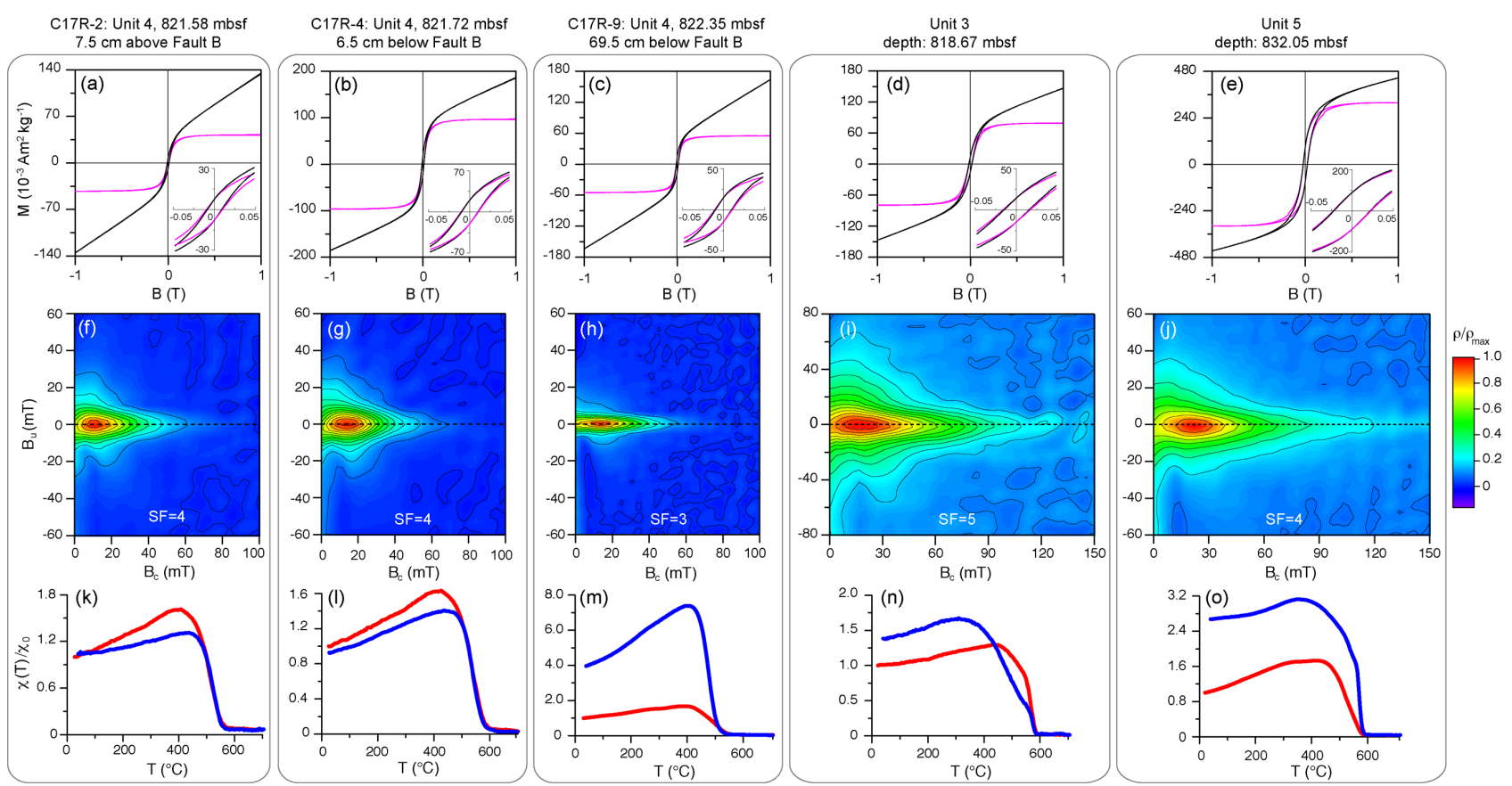

Figure 3. Rock magnetic properties of representative sheared clay samples from core 17R (Unit 4) with different distances to Fault B shown in Fig. 1(c), samples from the prism (Unit 3) and underthrust sediments (Unit 5). (a-e) Hysteresis loops before (dark lines) and after (magenta lines) correction for the paramagnetic contribution. Insets show close-up views of the central part of the hysteresis loops $( \pm 0.05 \mathrm{~T})$. (f-j) First-order reversal curve (FORC) diagrams processed with the FORCinel package (Harrison \& Feinberg 2008) with the VARIFORC option not used. For each sample, the optimal smoothing factor (SF) was calculated and applied. Each diagram is scaled to its maximum FORC density $\left(\rho_{\max }\right)$. $(\mathrm{k}-\mathrm{o})$ Magnetic susceptibility versus temperature $(\chi-T)$ cycles from room temperature to $700^{\circ} \mathrm{C}$ in argon. Each curve is normalized by the initial magnetic susceptibility at room temperature $\left(\chi_{0}\right)$. Red and blue lines indicate heating and cooling runs, respectively.
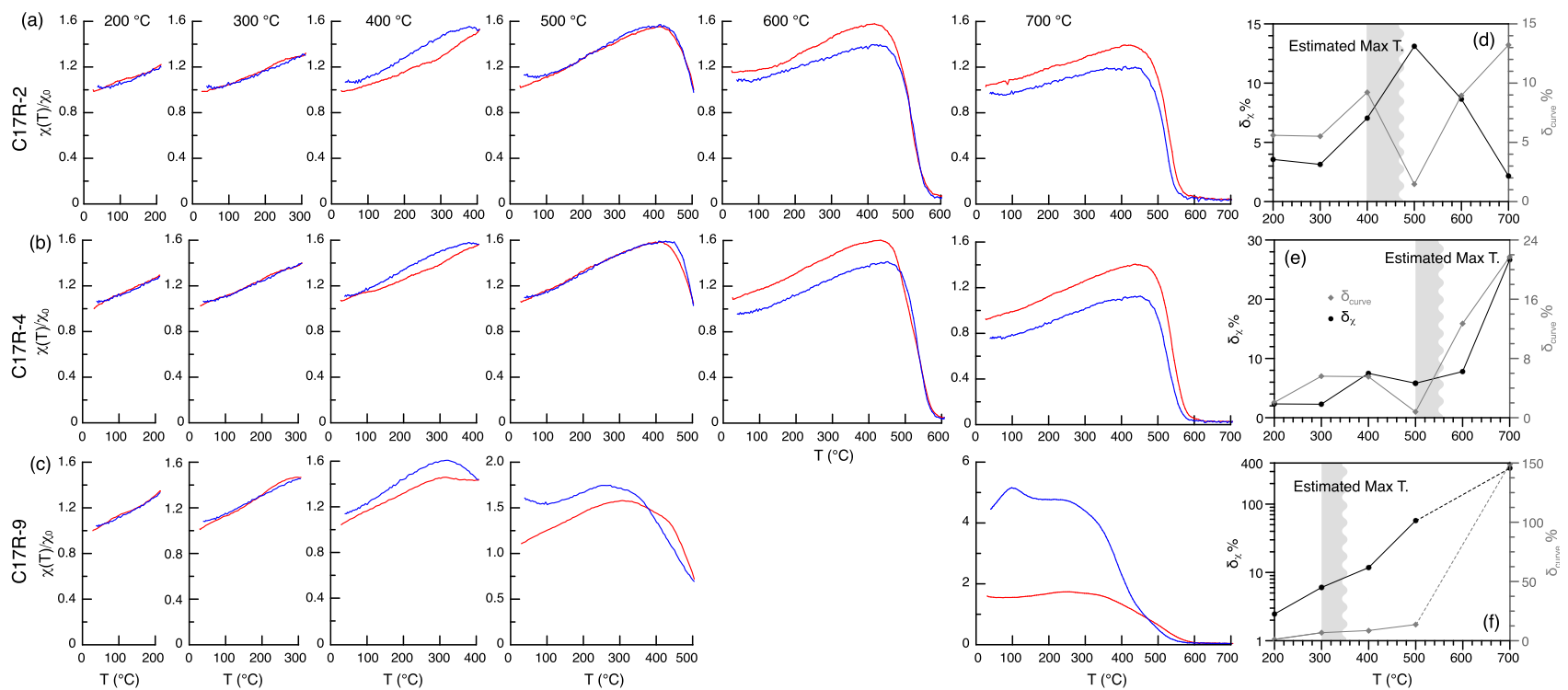

Figure 4. (a-c) $\chi-T$ curves of representative sheared clay samples upon stepwise heating/cooling cycles in argon to increasingly elevated temperature. The heating/cooling curves are normalized by the initial magnetic susceptibility $\left(\chi_{0}\right.$, Table 1$)$ before the thermal experiments. The maximum temperatures are subsequently $200,300,400,500,600$ and $700^{\circ} \mathrm{C}$. Red and blue lines indicate heating and cooling runs, respectively. (d-f) Alteration parameters $\left(\delta_{\chi}\right.$ : black dots and $\delta_{\text {curve }}$ : grey diamonds) versus heating temperature during the stepwise heating/cooling cycles. Shaded bands indicate the estimated maximum temperature ranges on basis of that no significant magnetic mineralogical alteration occurred during heating treatment, namely, both of $\delta_{\chi}$ and $\delta_{\text {curve }}$ are $<10$ per cent. The reader is referred to Table 1 and Fig. 1(c) for more details about sample locations.

$200^{\circ} \mathrm{C}$ (Table 1, Figs S3c and g). It may indicate that the clast has never been subjected to heating over $200^{\circ} \mathrm{C}$ in nature. Similar thermal behaviour is also observed on two samples from Units 3 and 5 , both are $\sim 2 \mathrm{~m}$ away from Unit 4 . It indicates that the thermal alteration effects start at a much lower temperature in 'normal' unheated samples than in the sheared samples close to slip surfaces in the Unit 4, which underwent frictional heating during previous earthquakes. 
Table 1. Values of the alteration index for magnetic susceptibility $\left(\delta_{\chi}\right)$ calculated with eq. (1), and for the heating/cooling runs $\left(\delta_{\text {curve }}\right)$ from eq. $(2)$ of seven samples from the plate-boundary fault zone, during different heating and cooling cycles.

\begin{tabular}{|c|c|c|c|c|c|c|c|c|c|c|c|c|c|c|c|}
\hline \multirow[t]{2}{*}{ Sample } & \multirow{2}{*}{$\begin{array}{l}\text { Depth } \\
\text { (mbsf) }\end{array}$} & \multirow[t]{2}{*}{ Description $^{a}$} & \multirow{2}{*}{$\begin{array}{c}\text { Starting } \chi_{0} \\
\left(10^{-8} \mathrm{~m}^{3} \mathrm{~kg}^{-1}\right)\end{array}$} & \multicolumn{2}{|c|}{$200^{\circ} \mathrm{C}$} & \multicolumn{2}{|c|}{$300^{\circ} \mathrm{C}$} & \multicolumn{2}{|c|}{$400^{\circ} \mathrm{C}$} & \multicolumn{2}{|c|}{$500^{\circ} \mathrm{C}$} & \multicolumn{2}{|c|}{$600^{\circ} \mathrm{C}$} & \multicolumn{2}{|c|}{$700^{\circ} \mathrm{C}$} \\
\hline & & & & $\begin{array}{l}\delta_{x} \\
\%\end{array}$ & $\begin{array}{c}\delta_{\text {curve }} \\
\%\end{array}$ & $\begin{array}{l}\delta_{x} \\
\%\end{array}$ & $\begin{array}{c}\delta_{\text {curve }} \\
\%\end{array}$ & $\begin{array}{l}\delta_{\chi} \\
\%\end{array}$ & $\begin{array}{c}\delta_{\text {curve }} \\
\%\end{array}$ & $\begin{array}{l}\delta_{x} \\
\%\end{array}$ & $\begin{array}{c}\delta_{\text {curve }} \\
\%\end{array}$ & $\begin{array}{l}\delta_{x} \\
\%\end{array}$ & $\begin{array}{c}\delta_{\text {curve }} \\
\%\end{array}$ & $\begin{array}{l}\delta_{x} \\
\%\end{array}$ & $\begin{array}{c}\delta_{\text {curve }} \\
\%\end{array}$ \\
\hline C17R-1 & 821.54 & $0.5 \mathrm{~cm}$ above Fault $\mathrm{A}$ & 77.97 & 0.3 & 2.4 & 0.9 & 3.1 & 6.1 & 7.7 & 9.1 & 5.4 & 50.3 & 10.0 & 165.3 & 36.2 \\
\hline C17R-3 & 821.63 & $2.5 \mathrm{~cm}$ above Fault B & 57.21 & 2.5 & 6.7 & 3.5 & 3.6 & 8.9 & 9.8 & 8.6 & 3.7 & 5.5 & 10.8 & 6.4 & 15.5 \\
\hline C17R-4 & 821.72 & $6.5 \mathrm{~cm}$ below Fault B & 132.06 & 2.3 & 2.1 & 2.3 & 5.6 & 7.5 & 5.5 & 5.8 & 0.8 & 7.8 & 12.7 & 26.7 & 21.7 \\
\hline C17R-5 & 821.78 & Mudstone clast & 48.34 & 12.0 & 4.9 & 8.2 & 7.7 & 14.5 & 3.3 & 20.3 & 3.7 & 28.5 & 8.6 & 36.9 & 11.7 \\
\hline
\end{tabular}

${ }^{a}$ Note: For the positions of Faults A and B refer to Fig. 1(c).
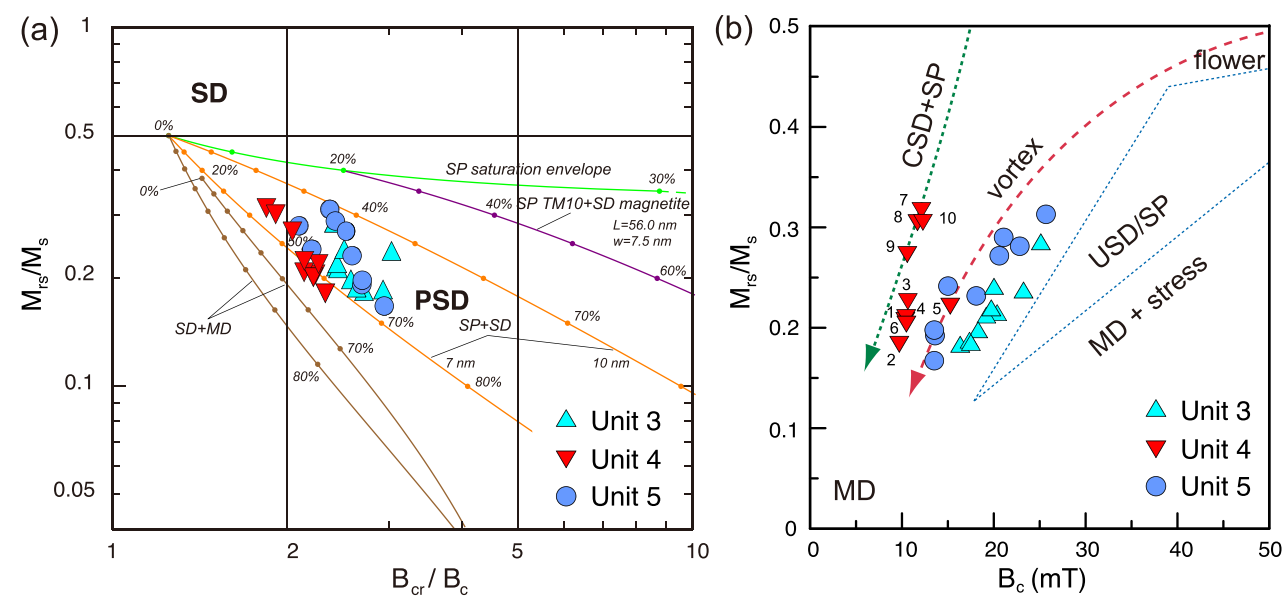

Figure 5. (a) Day plot of the hysteresis ratios $M_{\mathrm{rs}} / M_{\mathrm{s}}$ and $B_{\mathrm{cr}} / B_{\mathrm{c}}$ of core sediments. Single-domain (SD), pseudo-single-domain (PSD) and multidomain (MD) boundaries are after Dunlop (2002). Numbers adjacent to curves are volume fractions of the soft component (superparamagnetic, SP or MD) in mixtures with SD grains. (b) Squareness $\left(M_{\mathrm{rs}} / M_{\mathrm{S}}\right)$ versus coercivity $\left(B_{\mathrm{c}}\right)$ plot of core sediments. Boundaries for cubic SD $(\mathrm{CSD})+\mathrm{SP}$ and vortex-state trend lines; flower-state, uniaxial SD (USD)/SP and MD+stress fields are after Tauxe et al. (2002). Numbers adjacent to sample points are suffixes of sample number (C17R-n). The reader is referred to Table 1 and Fig. 1(c) for more details about sample locations.

\section{DISCUSSION}

\subsection{Magnetic minerals and their grain size in the plate-boundary fault zone}

Magnetite is the dominant magnetic carrier in all sediment samples. Small amounts of other magnetic minerals are also present in several samples. For example, sheared clays C17R-2, C17R-6, and C17R-9 show a small increase in magnetic susceptibility after heating to $400^{\circ} \mathrm{C}$ (Figs $4 \mathrm{a}, \mathrm{c}$ and S3d), indicating the presence of maghemite or partially maghemitized magnetite, which is reported to transform into magnetite on heating over $300^{\circ} \mathrm{C}$ in an argon atmosphere (e.g. Gehring et al. 2009). Its occurrence is also supported by the orange-brown and dark-brown colours of the sediment (Fig. 1c). The identification of pyrrhotite with a Curie temperature of $320^{\circ} \mathrm{C}$ in the final cooling branch of sample C17R-6 (Figs S1k and S3d), that is after heating to $700^{\circ} \mathrm{C}$, suggests the presence of Fe-sulphides (e.g. pyrite) in the original sediment. Further, $\chi$ peaks at $\mathrm{ca} .450^{\circ} \mathrm{C}$ on the heating branches for some sheared clays, prism (Unit 3) and underthrust (Unit 5) sediments (Figs 3m-o, S1a, 1 and S2) might result from detachment of adsorbed iron coatings in clay minerals with neoformation of ferrimagnetic minerals, as evidenced by a significantly increased $\chi$ after cooling to room temperature.

On a Day plot (Day et al. 1977), the magnetic minerals from the frontal prism and underthrust sediments are located in the PSD range (Fig. 5a), and between the SP(7 nm) $+\mathrm{SD}$ and $\mathrm{SP}(10 \mathrm{~nm})$
+ SD mixing curves of Dunlop (2002). The sheared clay samples (Unit 4) show up at a remarkable position on the Day plot: they move slightly towards to SD field and most of them distribute along the $\mathrm{SP}(7 \mathrm{~nm})+\mathrm{SD}$ mixing curve. This is compatible with their higher $\chi_{\mathrm{fd}}$ per cent values (Fig. 2). When plotted on a squareness versus coercivity plot (e.g. Tauxe et al. 2002), the fault zone samples (Unit 4) show a distinct trend (Fig. 5b). While the frontal prism (Unit 3) and underthrust (Unit 5) sediments broadly plot on the flower-state - vortex-state trend line, the fault zone samples plot on the cubic SD+SP trend line, consistent with their distribution on the Day plot (Fig. 5a). The reason for this is not clear at present; we speculate that the rupture slip would reduce the particle size: particles would become fine-grained spherical aggregates. This would result in a reduced uniaxial character of the anisotropy structure in the individual particles, that is the shape dominance would be removed. It is noteworthy that the mudstone clast which has been warmed to lower temperatures $\left(<200^{\circ} \mathrm{C}\right)$ plots in the vortex domain (Fig. 5b). It is also remarkable that samples in the immediate vicinity of the slip contact (C17R-1 to -4, Fig. 1c) plot more to the SP end member (i.e. towards to a lower squareness) than those several tens of centimetres away from the slip contact itself but still within the inferred plate-boundary fault zone (C17R-7 to C17R-10). It could be that the former have been more warmed and/or crushed by fault slip than the latter, which would lead to slightly finer particle aggregates. 


\subsection{Applicability of the rock magnetic 'geothermometer'}

The temperature estimation method used here is essentially based on testing the reversibility of heating and cooling branches during $\chi-T$ measurements to a set of increasing maximum temperatures. Its success crucially depends on the composition of the rock studied (Hrouda et al. 2003). Most of the paramagnetic and ferrimagnetic Fe-bearing minerals are thermally stable below $\sim 250{ }^{\circ} \mathrm{C}$ (Murad \& Wagner 1998; Henry 2007); at higher temperatures, some of them will start to alter. For example, siderite, which is a common subsidiary mineral in fault zones, starts to decompose to magnetite at $\sim 250^{\circ} \mathrm{C}$ (e.g. Isambert et al. 2003). The maximum heating temperature of the furnace attached to a MFK1 susceptometer is $700^{\circ} \mathrm{C}$. Therefore, it is feasible to infer temperatures of seismic frictional heating between $250-300$ and $700{ }^{\circ} \mathrm{C}$ by progressive $\chi-T$ measurements. Here we show by using increments of $100^{\circ} \mathrm{C}$ the proof of concept of this approach. Partial $\chi-T$ cycles with a smaller temperature increment would be helpful for obtaining more precise temperature estimates. With a dedicated furnace that would enable heating to a higher temperature, also temperatures $>700^{\circ} \mathrm{C}$ would be subject to scrutiny. If continued reaction would occur between 700 and $800{ }^{\circ} \mathrm{C}$, the $\chi-T$ cycle to $700{ }^{\circ} \mathrm{C}$ is reversible while that up to $800^{\circ} \mathrm{C}$ is emerging by a higher or lower cooling segment below $580^{\circ} \mathrm{C}$, the magnetic ordering temperature of magnetite. Along similar lines, changes in hysteresis loops and their parameters on stepwise heating (Henry et al. 2005) would also be a potential 'magnetic geothermometer' to estimate seismic frictional heating temperatures.

\subsection{Comparison to other frictional heating thermometers}

There are several other thermometry techniques available to detect the frictional heating signature of seismic slip within fault zones. Vitrinite reflectance, fission-track, and biomarkers appear particularly promising (d'Alessio et al. 2003; Fulton \& Harris 2012; Savage et al. 2014). Sometimes an approach requires a specific lithology to be applicable: vitrinite reflectance and biomarkers require sediments that contain certain types of organic matter, and fission track requires the presence of uranium-rich inclusions in certain minerals. Vitrinite reflectance, which can sense temperatures over a range from $\sim 25$ to $\sim 400^{\circ} \mathrm{C}$ (Mukhopadhyay 1992), is only applicable in sedimentary rocks containing woody plant material (Savage et al. 2014). Shear strain increases the vitrinite reflectance and as such complicates the calibration of the reflectance to temperature (Mastalerz et al. 1993). Biomarker thermal maturity indices measure the alteration of extractable organic material (e.g. diamondoids and short-chain alkanes) as a consequence of exposure to higher temperatures. It can be employed for investigating heating at a very wide temperature range: from geologic burial temperatures to as high as $\sim 800$ to $\sim 1000{ }^{\circ} \mathrm{C}$ (Polissar et al. 2011; Sheppard et al. 2015). For a meaningful application, the fault and the surrounding rock should have the same original hydrocarbon population before the slip event(s) (Savage et al. 2014). It cannot be applied to crystalline rocks and metamorphic rocks with all hydrocarbons destroyed (Savage et al. 2014). Fission tracks can only image frictional heating at the low temperature end, as fission tracks are 'reset' once temperature is sufficiently elevated (d'Alessio et al. 2003; Polissar et al. 2011), this is $>120^{\circ} \mathrm{C}$ for apatite, $>250{ }^{\circ} \mathrm{C}$ for zircon, and $>300^{\circ} \mathrm{C}$ for titanite (Garver 2008).

The rock magnetic 'geothermometer' explored here seems to be less lithology-dependent, for example, it can also be applied to volcanic rocks and weakly metamorphic sediments (Hrouda 2003).
In its present set-up, it senses medium temperature rise from $\sim 300$ to $\sim 700^{\circ} \mathrm{C}$. Therefore, it would be a complementary tool for detecting temperature rise in a range not covered by other methods. It would also be attractive for certain lithologies which cannot be assessed with more classical thermometry techniques. Future work to better constrain heat generation at a fault during an earthquake, could focus on establishing a kinetic model of thermal transformation of magnetic minerals as well as Fe-bearing clay minerals (which may produce magnetic minerals on heating) that involves the effects of flash temperature and mechanochemical reaction at fast sliding conditions.

\subsection{Seismic heating signature within the plate-boundary fault zone}

The cumulative displacement across the plate boundary at site C0019 is estimated to be $\sim 3.2 \mathrm{~km}$ (Chester et al. 2013b). The $50 \mathrm{~m}$ coseismic slip of the 2011 Tohoku-oki event accounts maximally for only about half of the plate motion since the A.D. 869 Jogan earthquake. So, earlier (large) earthquakes should have caused the remainder, when distributed (aseismic) slip is excluded. The multiple slip surfaces in the upper part of core 17R (Fig. 1c) indicate that seismic slip occurred repeatedly in the deformation history of the plate-boundary fault zone (Kirkpatrick et al. 2015). Besides the latest 2011 event, a series of magnitude (M) 7-class earthquakes have been recorded at the plate-boundary of the Japan Trench during the last several decades, such as the 1968 Tokachi-oki $\left(M_{\mathrm{w}} 8.3\right)$, 1978 Miyagi-oki (M 7.4), 1994 Sanriku-haruka-oki $\left(M_{\mathrm{w}} 7.7\right), 2005$ Miyagi-ken-oki $\left(M_{\mathrm{w}} 7.2\right), 2011$ Sanriku-oki ( $\left.M_{\mathrm{w}} 7.4\right)$ earthquakes (e.g. Umino et al. 2006; Suito et al. 2011).

Taking Fault B (Fig. 1c), for instance, as the slip zone of the 2011 Tohoku-oki event, we modelled temperature evolution within the fault zone on the basis of a 1-D thermal diffusion model with a finite fault thickness (Cardwell et al. 1978; see also Supporting information Text S1). According to the model with a shear stress of $0.56 \mathrm{MPa}$ (Fulton et al. 2013) and a slip zone of $0.3 \mathrm{~cm}$ width (Kirkpatrick et al. 2015), the peak temperature at the slip surface plane is about $800-1000{ }^{\circ} \mathrm{C}$, and the frictional heating rises the sediment's temperature up to $\sim 300^{\circ} \mathrm{C}$ within $\sim 2 \mathrm{~cm}$ of the fault zone (Fig. 6a). This result is consistent with the modelled maximum temperatures obtained from high-velocity friction experiments conducted by Ujiie et al. (2013) on sheared clays from Unit 4. The experiments were executed with water-saturated clays to mimic nature. Ujiie et al. (2013) determined a maximum temperature of $300^{\circ} \mathrm{C}$ for a displacement of $50 \mathrm{~m}$ under so-called impermeable conditions (then wall rock is tight so that fluid remains within the gouge zone). A maximum temperature of $800^{\circ} \mathrm{C}$ was obtained for a displacement of $35 \mathrm{~m}$, but now in permeable conditions. The wall rock absorbs the fluids to a large extent leading to a drained gouge zone which implies higher friction-induced temperatures. The occurrence of seismic heating is also evident from a temperature anomaly of $0.31{ }^{\circ} \mathrm{C}$ centred on the plate-boundary fault zone, measured 16 months after the rupture of 2011 earthquake event (Fulton et al. 2013).

Elevated temperatures are inferred as well from the presence of cubic SD+SP magnetite in the sheared clays. Seismic frictional heating is interpreted to have induced thermal generation of ferrimagnetic minerals from iron-bearing minerals, such as smectite, which occurs in large amounts in the clays in the plate-boundary fault zone (smectite contents are $>70$ per cent; Kameda et al. 2015). In laboratory experiments heating of smectite over $250{ }^{\circ} \mathrm{C}$ induces the authigenesis of fine-grained magnetite (Hirt et al. 1993). The 


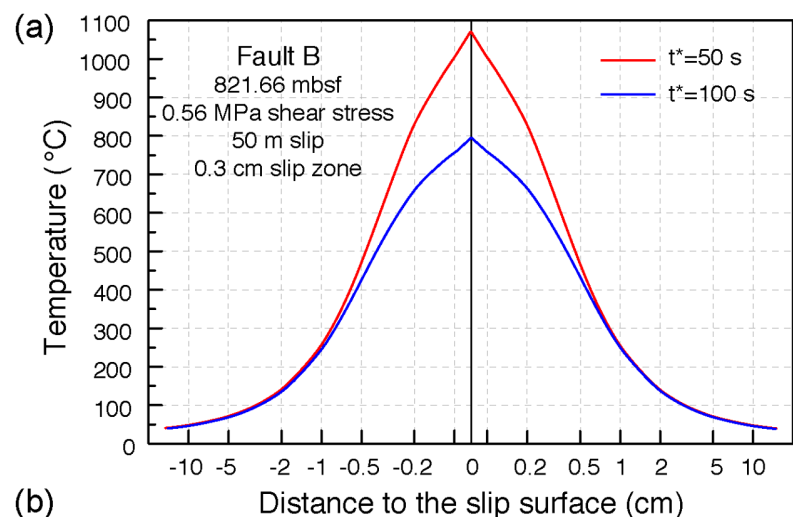

(b)

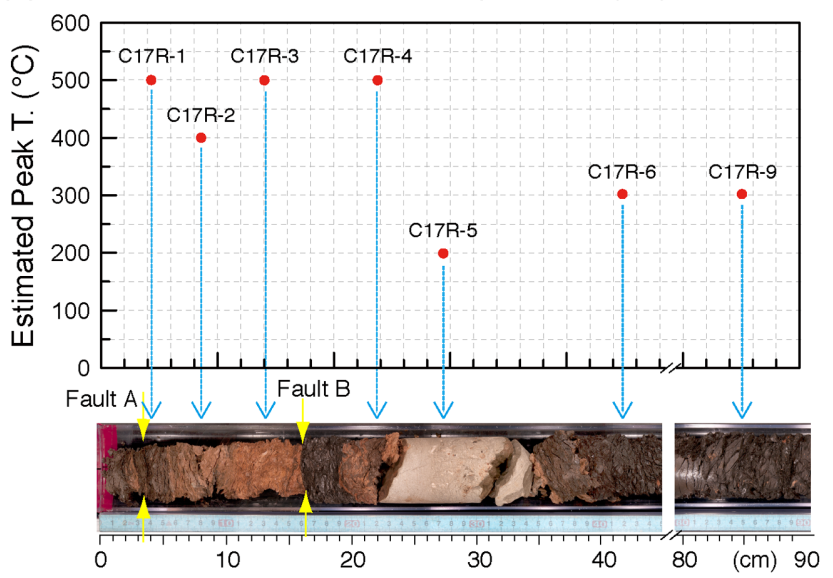

Figure 6. (a) Modelled peak temperature across Fault B due to the frictional heating associated with the 2011 Tohoku-oki earthquake for different slip durations $\left(t^{*}\right)$, on the basis of a 1-D thermal diffusion model with a finite fault thickness (Cardwell et al. 1978, see also Supporting Information Text S1). $x=0$ indicates the centre of the slip zone. (b) Maximum temperature rise experienced at different distances to slip zone estimated from the progressive magnetic susceptibility versus temperature measurements. Note that sample C17R-1 might be predominantly associated with slip of Fault A, while samples C17R-2 to C17R-4 would be primarily associated with slip of Fault B. Along similar lines, samples C17R-6 and C17R-9 may be associated with the inferred fault at the lower boundary of mudstone interval (Kirkpatrick et al. 2015) or to yet unidentified slip zone(s) (recall that in that interval core recovery is incomplete). Given the high seismic activity in the region, all (inferred) faults express the cumulative effects of multiple earthquake ruptures.

thermally affected magnetic phases within the fault zone are subsequently preserved. Based on our annealing experiments, the maximum natural annealing temperatures are estimated as $400-500^{\circ} \mathrm{C}$ in the upper part of the core 17R (Fig. 6b). In its lower part, the heating signatures with a lower estimated maximum temperature of $300^{\circ} \mathrm{C}$ revealed in samples C17R-6 and -9 may hint at the possibility of yet unidentified slip zone(s), like those suggested by Rabinowitz et al. (2015) just below the décollement. It is worthwhile to note that samples closest to fault slip zones (C17R-1: $0.5 \mathrm{~cm}$ above Fault A, C17R-3 and -4: $2.5 \mathrm{~cm}$ above and $6.5 \mathrm{~cm}$ below Fault B, respectively) show a higher estimated temperature (close to $600{ }^{\circ} \mathrm{C}$ ). This observation is consistent with the diffusion pattern of seismic frictional heating, which decays rapidly with distance from the principal slip surface (Fig. 6a). As discussed in Section 5.1, another candidate cause for the presence of finer grained magnetite in the sheared clay, especially close to Faults A and B (i.e. samples
C17R-1 to -4), is grinding of pre-existing magnetite grains due to the intensive shearing during the high-rate seismic slip.

These seismic friction temperature estimates assume that no significant post-seismic alteration has occurred. Within a fault zone, hydrothermal fluid flow is the most likely process that could alter magnetic mineralogy. However, geochemical analysis of pore waters and well logging revealed no significant active fluid flow along the plate boundary fault (Chester et al. 2013a; Fulton et al. 2013). We thus can rule out significant post-seismic alterations of the heating-induced magnetic signature. Furthermore, as hydrous clays ( $>60$ per cent) dominate the fault zone (Kameda et al. 2015), their endothermic dehydration reactions (e.g. Hirono et al. 2008) are estimated to consume $10-50$ per cent of the total mechanical energy input by seismic slip (Brantut et al. 2011). They thus attenuate the temperature rise in the fault zone. These would explain the large discrepancies between the modelled peak temperatures that only consider thermal conduction and assign the total $50 \mathrm{~m}$ coseismic slip to only one fault (Fig. 6a) and those estimated from the magnetic analysis (Fig. 6b). Further, rather than the plate-boundary fault (Unit 4), several candidate faults above and below have recently been proposed to have accommodated the 2011 Tohoku-oki earthquake (Rabinowitz et al. 2015). It remains hard and often (near to) impossible to relate a certain slip zone to a specific earthquake event.

The inferred temperatures here should be considered as maximum temperatures reached in nature, that is they are upper bounds. It is hard to extract the cumulative nature of a multitude of earthquakes rupturing along a certain slip zone. Also, a rather large temperature increment $\left(100^{\circ} \mathrm{C}\right)$ was used here during the progressive $\chi-T$ measurements. Nonetheless, the measurements provide thermal evidence of previous earthquakes that occurred at the plate-boundary of the Japan Trench, as well as constraints for understanding how their energy was dissipated. Importantly, it illustrates the validity of the proof of concept of the suggested rock magnetic 'geothermometer' in seismic fault zones. Other workers are encouraged to apply it to other seismic fault zones, and compare it with other geothermometers. As most geothermometers are sensitive to certain temperature intervals and effective in certain lithologies, combined application of several thermometers would yield a most robust picture of seismic frictional heating.

\section{CONCLUSIONS}

Stepwise progressive magnetic susceptibility versus temperature measurements were conducted on sheared clay from the Japan Trench subduction plate-boundary décollement, that is considered to have accommodated the large coseismic slip of the $2011 M_{\mathrm{W}} 9.0$ Tohoku-oki earthquake. Results revealed seismic heating signatures with estimated temperatures of $300-500{ }^{\circ} \mathrm{C}$ close to multiple localized slip surfaces. They provide reasonably robust thermal records of previous earthquake slip events that occurred within the plateboundary fault zone. This offers thermal boundary constraints for studies into the physical and chemical processes in décollement zone. It also demonstrates that this magnetic method can be used as a fault zone 'geothermometer' to determine medium temperature rise associated with earthquake slip. It would be a promising complementary approach for temperature ranges not covered by other methods. Further, the method seems less dependent on lithology requirements in fault zones when compared to more classical thermometry techniques (e.g. hydrocarbons for biomarker thermal maturity, woody organic matter for vitrinite reflectance). 


\section{ACK NOWLEDGEMENTS}

The core samples used in this study were provided by the Integrated Ocean Drilling Program (IODP). We thank all drilling staff and laboratory technicians on board the $\mathrm{D} / \mathrm{V}$ Chikyu during the Expedition 343. IODP-China provided funding for T. Yang's travel to work onboard and part of the post-cruise study. This work was supported by National Science Foundation of China (NSFC) grants Nos. 41472177 and 41204062 . We would like to thank the Editor Andrew Biggin, Bernard Henry, Art McGarr, Erwin Appel and an anonymous reviewer for their comments which helped to improve earlier versions of the manuscript. We are also indebted to Simo Spassov for his contribution to the interpretation and discussion of the hysteresis parameters. T. Yang acknowledges the China Scholarship Council (CSC) for a visiting scholarship to Utrecht University (The Netherlands).

\section{REFERENCES}

Argus, D.F., Gordon, R.G. \& DeMets, C., 2011. Geologically current motion of 56 plates relative to the no-net-rotation reference frame, Geochem. Geophys. Geosyst., 12(11), Q11001, doi:10.1029/2011GC003751.

Brantut, N., Han, R., Shimamoto, T., Findling, N. \& Schubnel, A., 2011. Fast slip with inhibited temperature rise due to mineral dehydration: evidence from experiments on gypsum, Geology, 39(1), 59-62.

Cardwell, R.K., Chinn, D.S., Moore, G.F. \& Turcotte, D.L., 1978. Frictional heating on a fault zone with finite thickness, Geophys. J. R. astr. Soc., 52(3), 525-530.

Chester, F.M., Mori, J.J., Eguchi, N. \& Toczko, S., Expedition 343/343T Scientists, 2013a. Proceedings of the Integrated Ocean Drilling Program, Vol. 343/343T, Integrated Ocean Drilling Program Management International, Inc., Tokyo, doi:10.2204/iodp.proc.343343T.2013.

Chester, F.M. et al., 2013b. Structure and composition of the plate-boundary slip zone for the 2011 Tohoku-Oki earthquake, Science, 342(6163), 12081211.

d'Alessio, M.A., Blythe, A.E. \& Buürgmann, R., 2003. No frictional heat along the San Gabriel fault, California: evidence from fission-track thermochronology, Geology, 31(6), 541-544.

Day, R., Fuller, M. \& Schmidt, V.A., 1977. Hysteresis properties of titanomagnetites: grain-size and compositional dependence, Phys. Earth planet. Inter., 13, 260-267.

Dekkers, M.J., 1997. Environmental magnetism: an introduction, Geol. Mijnbouw, 76, 163-182.

Dunlop, D.J., 2002. Theory and application of the Day plot $\left(\mathrm{M}_{\mathrm{rs}} / \mathrm{M}_{\mathrm{S}}\right.$ versus $\mathrm{H}_{\mathrm{cr}} / \mathrm{H}_{\mathrm{c}}$ ): 1 . Theoretical curves and tests using titanomagnetite data, $J$. geophys. Res., 107(B3), 2056, doi:10.1029/2001JB000486.

Dunlop, D.J. \& Özdemir, Ö., 1997. Rock Magnetism: Fundamentals and Frontiers, Cambridge Univ. Press, 573 pp.

Egli, R., Chen, A.P., Winklhofer, M., Kodama, K.P. \& Horng, C.-S., 2010. Detection of noninteracting single domain particles using first-order reversal curve diagrams, Geochem. Geophys. Geosyst., 11, Q01Z11, doi:10.1029/2009GC002916.

Evans, M.E. \& Heller, F., 2003. Environmental Magnetism: Principles and Applications of Environmagnetics, Academic Press, 299 pp.

Fujiwara, T., Kodaira, S., No, T., Kaiho, Y., Takahashi, N. \& Kaneda, Y., 2011. The 2011 Tohoku-Oki earthquake: displacement reaching the trench axis, Science, 334(6060), 1240, doi:10.1126/science.1211554.

Fulton, P.M. \& Harris, R.N., 2012. Thermal considerations in inferring frictional heating from vitrinite reflectance and implications for shallow coseismic slip within the Nankai Subduction Zone, Earth planet. Sci. Lett., 335-336, 206-215.

Fulton, P.M. et al., 2013. Low coseismic friction on the Tohoku-Oki fault determined from temperature measurements, Science, 342(6163), 1214 1217.

Garver, J.I., 2008. Fission-track dating, in Encyclopedia of Paleoclimatology and Ancient Environments, pp. 247-249, ed. Gornitz, V., Springer.
Gehring, A.U., Fischer, H., Louvel, M., Kunze, K. \& Weidler, P.G., 2009. High temperature stability of natural maghemite: a magnetic and spectroscopic study, Geophys. J. Int., 179(3), 1361-1371.

Han, R., Shimamoto, T., Ando, J.-I. \& Ree, J.-H., 2007. Seismic slip record in carbonate-bearing fault zones: an insight from high-velocity friction experiments on siderite gouge, Geology, 35(12), 1131-1134.

Hanesch, M., Stanjek, H. \& Petersen, N., 2006. Thermomagnetic measurements of soil iron minerals the role of organic carbon, Geophys. J. Int., $165,53-61$.

Harrison, R.J. \& Feinberg, J.M., 2008. FORCinel: an improved algorithm for calculating first-order reversal curve distributions using locally weighted regression smoothing, Geochem. Geophys. Geosyst., 9(5), Q05016, doi:10.1029/2008GC001987.

Hashimoto, C., Noda, A., Sagiya, T. \& Matsu'ura, M., 2009. Interplate seismogenic zones along the Kuril-Japan Trench inferred from GPS data inversion, Nat. Geosci., 2(2), 141-144.

Henry, B., 2007. Magnetic mineralogy, changes due to heating, in Encyclopedia of Geomagnetism and Paleomagnetism, pp. 512-515, eds Gubbins, D. \& Herrero-Bervera, E., Springer-Verlag.

Henry, B., Jordanova, D., Jordanova, N. \& Le Geoff, M., 2005. Transformations of magnetic mineralogy in rocks revealed by difference of hysteresis loops measured after stepwise heating: theory and case studies, Geophys. J. Int., 162(1), 64-78.

Heslop, D., 2015. Numerical strategies for magnetic mineral unmixing, Earth-Sci. Rev., 150, 256-284.

Hirono, T. et al., 2008. Clay mineral reactions caused by frictional heating during an earthquake: an example from the Taiwan Chelungpu fault, Geophys. Res. Lett., 35, L16303, doi:10.1029/2008GL034476.

Hirt, A.M., Banin, A. \& Gehring, A.U., 1993. Thermal generation of ferromagnetic minerals from iron-enriched smectites, Geophys. J. Int., 115(3), $1161-1168$.

Hrouda, F., 2003. Indices for numerical characterization of the alteration process of magnetic minerals taking place during investigation of temperature variation of magnetic susceptibility, Stud. Geophys. Geod., 47(4), $847-861$.

Hrouda, F., Müller, P. \& Hanák, J., 2003. Repeated progressive heating in susceptibility vs. temperature investigation: a new palaeotemperature indicator?, Phys. Chem. Earth, 28(16-19), 653-657.

Hunt, C.P., Moskowitz, B.M. \& Banerjee, S.K., 1995. Magnetic properties of rocks and minerals, in Rock Physics and Phase Relations: A Handbook of Physical Constants, pp. 189-204, ed. Ahrens, T.J., American Geophysical Union.

Isambert, A., Valet, J.P., Gloter, A. \& Guyot, F., 2003. Stable Mn-magnetite derived from Mn-siderite by heating in air, J. geophys. Res., 108(B6), 2283, doi:10.1029/2002JB002099.

Ishikawa, T. et al., 2008. Coseismic fluid-rock interactions at high temperatures in the Chelungpu Fault, Nat. Geosci., 1(10), 679-683.

Kameda, J., Shimizu, M., Ujiie, K., Hirose, T., Ikari, M., Mori, J., Oohashi, K. \& Kimura, G., 2015. Pelagic smectite as an important factor in tsunamigenic slip along the Japan Trench, Geology, 43(2), 155-158.

Kano, Y., Mori, J., Fujio, R., Ito, H., Yanagidani, T., Nakao, S. \& Ma, K.-F., 2006. Heat signature on the Chelungpu fault associated with the 1999 Chi-Chi, Taiwan earthquake, Geophys. Res. Lett., 33(14), L14306, doi:10.1029/2006GL026733.

Kirkpatrick, J.D. et al., 2015. Structure and lithology of the Japan Trench subduction plate boundary fault, Tectonics, 34(1), 53-69.

Kuo, L.-W., Song, S.-R., Huang, L., Yeh, E.-C. \& Chen, H.-F., 2011. Temperature estimates of coseismic heating in clay-rich fault gouges, the Chelungpu fault zones, Taiwan, Tectonophysics, 502(3-4), 315-327.

Lin, W., Fulton, P.M., Harris, R.N., Tadai, O., Matsubayashi, O., Tanikawa, W. \& Kinoshita, M., 2014. Thermal conductivities, thermal diffusivities, and volumetric heat capacities of core samples obtained from the Japan Trench Fast Drilling Project (JFAST), Earth Planets Space, 66, 48, doi:10.1186/1880-5981-66-48.

Liu, Q.S., Roberts, A.P., Larrasoaña, J.C., Banerjee, S.K., Guyodo, Y., Tauxe, L. \& Oldfield, F., 2012. Environmental magnetism: principles and applications, Rev. Geophys., 50, RG4002, doi:10.1029/2012RG000393. 
Mair, K., Renard, F. \& Gundersen, O., 2006. Thermal imaging on simulated faults during frictional sliding, Geophys. Res. Lett., 33, L19301, doi:10.1029/2006GL027143.

Mastalerz, M., Wilks, K.R., Bustin, R.M. \& Ross, J.V., 1993. The effect of temperature, pressure and strain on carbonization in high-volatile bituminous and anthracitic coals, Org. Geochem., 20(2), 315-325.

Mukhopadhyay, P.K., 1992. Maturation of organic matter as revealed by microscopic methods: applications and limitations of vitrinite reflectance, and continuous spectral and pulsed laser fluorescence spectroscopy, in Diagenesis, III: Developments in Sedimentology, Vol. 47, pp. 435-510, eds Wolf, K.H. \& Chilingarian, G.V., Elsevier.

Murad, E. \& Wagner, U., 1998. Clays and clay minerals: the firing process, Hyperfine Interact., 117(1-4), 337-356.

Pike, C.R., Roberts, A.P. \& Verosub, K.L., 1999. Characterizing interactions in fine magnetic particle systems using first order reversal curves, J. appl. Phys., 85(9), 6660-6667.

Polissar, P.J., Savage, H.M. \& Brodsky, E.E., 2011. Extractable organic material in fault zones as a tool to investigate frictional stress, Earth planet. Sci. Lett., 311(3-4), 439-447.

Rabinowitz, H.S., Savage, H.M., Plank, T., Polissar, P.J., Kirkpatrick, J.D. \& Rowe, C.D., 2015. Multiple major faults at the Japan Trench: chemostratigraphy of the plate boundary at IODP Exp. 343: JFAST, Earth planet. Sci. Lett., 423, 57-66.

Roberts, A.P., 2015. Magnetic mineral diagenesis, Earth-Sci. Rev., 151, $1-47$.

Roberts, A.P., Chang, L., Rowan, C.J., Horng, C.S. \& Florindo, F., 2011. Magnetic properties of sedimentary greigite $\left(\mathrm{Fe}_{3} \mathrm{~S}_{4}\right)$ : an update, Rev. Geophys., 49, RG1002, doi:10.1029/2010RG000336.

Roberts, A.P., Heslop, D., Zhao, X. \& Pike, C.R., 2014. Understanding fine magnetic particle systems through use of first-order reversal curve diagrams, Rev. Geophys., 52(4), 557-602.

Sakaguchi, A. et al., 2011. Seismic slip propagation to the updip end of plate boundary subduction interface faults: vitrinite reflectance geothermometry on Integrated Ocean Drilling Program NanTro SEIZE cores, Geology, 39(4), 395-398.

Savage, H.M., Polissar, P.J., Sheppard, R., Rowe, C.D. \& Brodsky, E.E., 2014. Biomarkers heat up during earthquakes: new evidence of seismic slip in the rock record, Geology, 42(2), 99-102.

Sheppard, R.E., Polissar, P.J. \& Savage, H.M., 2015. Organic thermal maturity as a proxy for frictional fault heating: experimental constraints on methylphenanthrene kinetics at earthquake timescales, Geochim. Cosmochim. Acta, 151, 103-116.

Simons, M. et al., 2011. The 2011 magnitude 9.0 Tohoku-Oki earthquake: mosaicking the megathrust from seconds to centuries, Science, 332(6036), 1421-1425.

Spassov, S. \& Hus, J., 2006. Estimating baking temperatures in a Roman pottery kiln by rock magnetic properties: implications of thermochemical alteration on archaeointensity determinations, Geophys. J. Int., 167(2), 592-604.

Suito, H., Nishimura, T., Tobita, M., Imakiire, T. \& Ozawa, S., 2011. Interplate fault slip along the Japan Trench before the occurrence of the 2011 off the Pacific coast of Tohoku Earthquake as inferred from GPS data, Earth Planets Space, 63(7), 615-619.

Tanikawa, W., Mishima, T., Hirono, T., Soh, W. \& Song, S.-R., 2008. High magnetic susceptibility produced by thermal decomposition of core samples from the Chelungpu fault in Taiwan, Earth planet. Sci. Lett., 272(1-2), 372-381.

Tauxe, L., 2010. Essentials of Paleomagnetism, University of California Press, 489 pp.

Tauxe, L., Bertram, H.N. \& Seberino, C., 2002. Physical interpretation of hysteresis loops: micromagnetic modeling of fine particle magnetite, Geochem. Geophys. Geosyst., 3(10), 1055, doi:10.1029/2001GC000241.

Ujiie, K. et al., 2013. Low coseismic shear stress on the Tohoku-Oki megathrust determined from laboratory experiments, Science, 342(6163), 12111214.

Umino, N. et al., 2006. Revisiting the three M 7 Miyagi-oki earthquakes in the 1930s: possible seismogenic slip on asperities that were re-ruptured during the $1978 \mathrm{M}=7.4$ Miyagi-oki earthquake, Earth Planets Space, 58(12), 1587-1592.
Verosub, K.L. \& Roberts, A.P., 1995. Environmental magnetism: past, present, and future, J. geophys. Res., 100(B2), 2175-2192.

Yang, T., Mishima, T., Ujiie, K., Chester, F.M., Mori, J.J., Eguchi, N., Toczko, S. \& Expedition 343 Scientists, 2013. Strain decoupling across the décollement in the region of large slip during the 2011 Tohoku-Oki earthquake from anisotropy of magnetic susceptibility, Earth planet. Sci. Lett., 381, 31-38.

Yue, H. \& Lay, T., 2011. Inversion of high-rate (1 sps) GPS data for rupture process of the 11 March 2011 Tohoku earthquake $\left(M_{\mathrm{W}} 9.1\right)$, Geophys. Res. Lett., 38, L00G09, doi:10.1029/2011GL048700.

\section{SUPPORTING INFORMATION}

Additional Supporting Information may be found in the online version of this paper:

Text S1. Modeling of peak temperature during seismic slip.

Figure S1. (a-d) Hysteresis loops, (e-h) FORC diagrams, and (i-1) $\chi-T$ curves of sheared clay samples from core $17 \mathrm{R}$ (Unit 4) with different distances to Faults A and B, as well as the mudstone interval (C17R-5) shown in Fig. 1(c). Refer to the caption to Fig. 3 (main text) for more details.

Figure S2. (a-c) Hysteresis loops, (d-f) FORC diagrams, and ( $\mathrm{g}-\mathrm{i}$ ) $\chi$-T curves of representative prism (Unit 3 ) and underthrust sediment (Unit 5) samples. Refer to the caption to Fig. 3 for more details.

Figure S3. (a-d) $\chi-T$ curves of representative sheared clay samples upon partial stepwise heating/cooling cycles in argon. (e-h) Alteration parameters ( $\delta_{\chi}$ : black dots and $\delta_{\text {curve }}$ : grey diamonds) versus heated temperature upon partial stepwise heating/cooling cycles. The reader is referred to the caption to Fig. 4 for more details. (http://gji.oxfordjournals.org/lookup/suppl/doi:10.1093/gji/ggw013 /-/DC1).

Please note: Oxford University Press is not responsible for the content or functionality of any supporting materials supplied by the authors. Any queries (other than missing material) should be directed to the corresponding author for the paper.

\section{APPENDIX: GLOSSARY}

Trace amounts of so-called magnetic minerals occur in essentially every geological material. More common natural magnetic minerals constitute several iron oxides (magnetite, maghemite, hematite and goethite) and some iron sulfides (pyrrhotite and greigite). Classically, palaeomagnetism involves a directional analysis of the ancient remanent magnetic moment referred to as natural remanent magnetization (NRM) that is locked into a rock during or shortly after its formation. This enables reconstruction of the palaeolatitude of rock formations under scrunity and determines whether or not vertical-axis rotation has occurred, both providing important boundary constraints for geological reconstructions.

The interpretation made in this contribution is based on a detailed evaluation of the magnetic properties of the rocks under investigation (there is no information on NRM behaviour). Some of these magnetic properties are dependent on the grain size of the magnetic particles because that is tied to the magnetic domain configuration in such particles. Next to information on the concentration of magnetic minerals, an analysis of grain size effects offers insight into to the geological processes that have affected the magnetic particle suite. Iron, a redox-sensitive element, can be mobilized during changes in the redox state in a rock sequence due to the action of fluids. At the same time such fluids can leach magnetic minerals 
or induce their precipitation. Rock or mineral magnetic methods offer four assets: (1) they can be applied to relatively large samples so unveal information typical of the entire rock, (2) they are grain size dependent so that fragmentation or grain growth of magnetic minerals can be quantified, (3) they are sensitive-strongly magnetic minerals can be measured down to the ppm level and (4) they are comparatively quick so that a fair amount of samples can be processed within a reasonable time.

Magnetic properties vary as a function of temperature and applied magnetic fields. Above a certain temperature, the magnetic ordering temperature or Curie temperature, collective magnetic coupling is removed by the action of thermal vibration of the crystal structure and all previous magnetic information is lost. Each magnetic mineral has a specific Curie temperature so its measurement reveals magnetic mineralogy. By studying the response of a sample to varying applied fields at a given temperature, usually room temperature, grain size dependent information can be retrieved. This is because various types of magnetic domain structures are dependent on particle size and they respond differently to applied magnetic fields. Extremely small particles $(<30 \mathrm{~nm}$ for magnetite at room temperature) cannot retain a stable magnetic structure, small single domain particles (30-80 $\mathrm{nm}$ for equant magnetite at room temperature) are extremely stable. With larger sizes the magnetic stability decreases.

Below we provide a concise explanation of the technical terms used in this contribution. Textbooks on palaeomagnetism include Tauxe (2010), on rock magnetism Dunlop \& Özdemir (1997) and on environmental magnetism, the study of magnetic properties applied to geological materials, Evans \& Heller (2003). Useful review papers on various aspects of magnetic minerals include Hunt et al. (1995), Verosub \& Roberts (1995), Dekkers (1997), Roberts et al. (2011), Liu et al. (2012), Roberts et al. (2014), Roberts (2015) and Heslop (2015).

Anisotropy of (low-field) magnetic susceptibility (AMS): A property of a material whereby identical alternating magnetic fields with a field strength of up to several times the Earth's magnetic field are applied in different directions to a sample. This produces an anisotropic, a slightly different induced magnetization as function of orientation. AMS reflects the statistical alignment of crystallographic directions and/or shape in platy or elongate grains.

Coercive force $\left(B_{\mathrm{c}}\right)$, coercivity of remanence $\left(B_{\mathrm{cr}}\right)$ : see hysteresis loops.

Curie temperature $\left(T_{\mathrm{c}}\right)$ : As temperature increases in a ferromagnetic (sensu lato) material, interatomic distances increase, and the magnetic exchange interaction that describes the collective ordering of atomic magnetic moments, becomes weaker. At $T_{\mathrm{c}}$, thermal energy overcomes the exchange energy, and individual atomic magnetic moments become independent (they lose their long-range ordering) so that the material becomes paramagnetic. Named after the French physicist Pierre Curie (1859-1906).

Ferrimagnetic: A state of magnetic order in which two ferromagnetic sublattices of unequal magnitude are aligned antiparallel to each other.

First-order reversal curve (FORC) diagrams: FORCs are partial hysteresis loops determined with the following procedure: (1) a positive saturation field is applied; (2) the field is ramped down to a lower reversal field; (3) the magnetization of the sample is measured while the applied field is ramped upward to positive saturation again. A series of FORCs is measured for a set of reversal fields that are increasingly away from positive saturation, and a FORC distribution is calculated as the mixed second derivative of magnetization with respect to field spacing; it is displayed in a so-called FORC diagram. FORC diagrams provide information about the distribution of switching fields (i.e. coercivities) and interaction fields for all magnetic particles that contribute to a hysteresis loop. They are widely used to characterize samples in rock and mineral magnetism.

Frequency dependent susceptibility: The difference between susceptibility measurements made at two frequencies (e.g. low $0.47 \mathrm{kHz}$, high $4.7 \mathrm{kHz}$ ). This measurement denotes the presence of magnetically 'viscous' ferrimagnetic (magnetite or maghaemite) grains lying at the stable single domain (SSD)/superparamagnetic (SP) boundary and their delayed response to the magnetizing field.

Hysteresis parameters: see magnetic hysteresis loop and parameters.

Magnetic domain: A portion of a ferromagnetic/ferrimagnetic material in which the atomic magnetic moments are aligned. In a magnetic material, magnetic domains serve to reduce the magnetostatic energy due to the aligned spontaneous magnetization. Fine magnetic grains are single domain and larger grains contain several magnetic domains. The magnetic domains form a structure in which the magnetic moments of individual magnetic domains cancel each other out as much as possible. As a result, the spontaneous magnetization of the overall magnetic body is reduced, leading to a lower magnetostatic energy state which represents a stable configuration.

Magnetic susceptibility: A measure of the ease with which a substance can be magnetized in small, Earth-like, applied magnetic fields. The magnetic moment divided by the field strength in units of $\mathrm{H}$ (i.e. $\mathrm{A} \mathrm{m}^{-1}$ ) is the susceptibility. Volume susceptibility $(\kappa)$ is the induced magnetization per unit volume divided by the field strength, and is a dimensionless quantity. Mass specific susceptibility $(\chi)$ is the magnetic moment expressed per unit of mass divided by the field strength; it has units of $\mathrm{m}^{3} \mathrm{~kg}^{-1}$, that is the inverse of the specific density of a material. Magnetic susceptibility depends principally on the type and concentration of magnetic minerals in a sample; grain-size dependence is marginal (with the exception of superparamagnetism).

Magnetic remanence: Magnetization that persists in the absence of an applied magnetic field. It differs from induced magnetization that disappears on removal of an applied field.

Magnetic hysteresis loop and parameters: A hysteresis loop results when the in-field magnetization of a sample is measured as the inducing field is cycled between high positive and negative values. A hysteresis loop can be obtained at any temperature; most hysteresis loops are acquired at room temperature. The shape of the hysteresis loop yields pertinent information about the magnetic mineral(s) present in a sample and, most importantly on their grain size. The maximum induced magnetization that can be induced in a sample is termed the saturation magnetization $\left(M_{\mathrm{s}}\right)$. The corresponding remanence, when the applied field is reduced to zero, is the saturation remanence $\left(M_{\mathrm{rs}}\right)$, and the reversed magnetic field required to reduce the magnetization to zero is the coercive force $\left(B_{\mathrm{c}}\right)$. The coercivity of remanence $\left(B_{\mathrm{cr}}\right)$ : The direct reversed magnetic field required to demagnetize to zero the saturation remanent magnetization that was imparted in the opposite direction.

Magnetic mineral: Minerals that are able to retain permanent magnetism at room temperature. In nature, these are restricted to several iron oxides and a few iron sulphides.

Magnetic saturation: The maximum magnetic moment a sample can achieve. Increasing the field strength even further does not impart a higher magnetic moment.

Magnetostatic interactions: When magnetic particles are located sufficiently close to each other, their magnetic fields will interact. The interaction field depends on the configuration of neighbouring particles and will be stronger if more adjacent particles are 
magnetized in the same direction. Magnetostatic interactions are an important factor to explain the magnetic properties of closelyspaced aggregates or intergrown magnetic particles in earth materials.

Multidomain (MD): With increasing size, its magnetostatic energy increases. In order to minimize this energy, a particle will begin to nucleate domain walls at a critical grain size threshold. These walls divide the particle into two or more magnetic volumes or domains. The magnetization is uniform in each domain, but it differs in direction from domain to domain.

Paramagnetism: The magnetic state in materials with uncompensated electron spins that do not behave collectively, that is each free electron spin is an individual atomic magnet. In an applied magnetic field these moments will partially align to that applied field: a paramagnetic material will be magnetized in the direction of its inducing magnetic field. When the field is removed, the induced magnetic moment disappears instantaneously.

Pseudo-single-domain (PSD): A magnetic structure that is intermediate between the single-domain (SD) and multidomain states. A PSD particle contains more than one domain (up to $\sim 7-10$ ) but exhibits many of the stable magnetic properties typical of SD particles.
Saturation magnetization $\left(M_{\mathrm{s}}\right)$, saturation remanence $\left(M_{\mathrm{rs}}\right)$ : see hysteresis loops.

Single-domain $(S D)$ : A uniformly magnetized magnetic particle with a single magnetic domain. In most ferro- and ferrimagnetic minerals, stable SD (SSD) grains are extremely small (the SD size range in magnetite is $\sim 30-80 \mathrm{~nm}$ ).

Superparamagnetism (SP): Class of magnetic behaviour exhibited by very small particles $(<30 \mathrm{~nm}$ in magnetite at room temperature) with relaxation times (magnetic decay time equivalent to the half-life of radioactive elements) of laboratory time scales (typically $<100 \mathrm{~s}$ ). For these particles, atomic magnetic moments align in low, Earth-like, applied magnetic fields to produce a strong induced magnetization that can be rapidly destroyed by thermal vibration soon after removing the field (seconds to minutes).

Temperature dependence of magnetic susceptibility $(\chi-T)$ : Measurement of magnetic susceptibility while heating up to certain temperatures and during subsequent cooling. This experiment provides useful information about the magnetic minerals and their evolution upon heating; particularly thermochemical changes can be evaluated. Also referred to as thermomagnetic cycling or thermomagnetic analysis. 